\title{
The Non-saying of What Should Have Been Said
}

\author{
Roberta Colonna Dahlman ${ }^{1}$ (D)
}

Received: 7 February 2021 / Accepted: 12 July 2021 / Published online: 19 August 2021

(c) The Author(s) 2021

\begin{abstract}
According to Grice's analysis, conversational implicatures are carried by the saying of what is said (Grice 1989: 39). In this paper, it is argued that, whenever a speaker implicates a content by flouting one or several maxims, her implicature is not only carried by the act of saying what is said and the way of saying it, but also by the act of non-saying what should have been said according to what would have been normal to say in that particular context. Implicatures that arise without maxim violation are only built on the saying of what is said, while those that arise in violative contexts are carried by the saying of what is said in combination with the non-saying of what should have been said. This observation seems to justify two claims: (i) that conversational implicatures have different epistemic requirements depending on whether they arise in violative or non-violative contexts; (ii) that implicatures arising in non-violative contexts are more strongly tied to their generating assertion than those arising with maxim violation.
\end{abstract}

Keywords Paul Grice · Conversational implicatures · Violative implicature contexts $\cdot$ Non-violative implicature contexts

\section{Implicature and conventional meaning}

In his William James lectures, delivered at Harvard University in 1967, Grice introduced the notion of implicature based on the empirical observation that speakers often mean more than what they say, that is, more than what their utterances literally mean. ${ }^{1}$ This 'more' is what an utterance can implicate, an implicature, a content the speaker intends to convey implicitly, that is, without explicitly saying it. In 'Logic and Conversation,' Grice proposed the distinction between

\footnotetext{
1 On the Gricean notion of 'what is said', and the distinction between 'what is said' and 'what is communicated,' see Borg \& Fisher (forthcoming).

Roberta Colonna Dahlman

roberta.colonna_dahlman@rom.lu.se

1 Centre for Languages and Literature, Lund University, Box 201, 22100 Lund, Sweden
} 
conventional and conversational implicatures (Grice, 1989: 25-26). In the former case, it is the conventional meaning of the words used that determines what is implicated, besides determining what is said (Grice, 1989: 25). The example offered by Grice is the implicature depending on the word 'therefore,' that is used to express a consequential relation between two statements (Grice, 1989: 25). In uttering a sentence such as 'Dwight is an Englishman, therefore he is brave,' the speaker says that Dwight is an Englishman and that he is a brave man, and, at the same time, it is reasonable to assume that she intends to implicate a consequential relation between Dwight being an Englishman and his being brave, that is, his bravery is a consequence of his being an Englishman.

By contrast, conversational implicatures are essentially connected with certain general discourse features, in particular with the assumption that talk exchanges typically are cooperative efforts. According to Grice's well-known Cooperative Principle, language users are expected to make their conversational contribution "such as is required, at the stage at which it occurs, by the accepted purpose or direction of the talk exchange" in which they are engaged (Grice, 1989: 26). The Cooperative Principle is further spelled out in four types of conversational maxims: maxims of Quantity ('Be informative'), maxims of Quality ('Try to make your contribution one that is true'), maxim of Relation ('Be relevant') and maxims of Manner ('Be perspicuous').

The interlocutors' knowledge of the conventional meaning of the words used ('what is said') is an essential condition for conveying and understanding implicated meaning ('what is meant'). As said, on the one hand, conventional implicatures are entirely determined by the conventional meaning of the words used. On the other hand, conversational implicatures are not (or are not only) determined by the conventional meaning of the words used, but rather by the fact that the speaker says what she says in a certain conversational context. However, even in this case, the fact that both speaker and hearer know the conventional meaning of the words used is a fundamental condition for a successful communicative exchange. This Grice underlines when he writes that, for a conversational implicature to arise in a given context, it is necessary that a speaker be able to use properly the conventional meaning of a sentence, that is, to be fully aware, while producing a sentence, of what she is saying:

If nonconventional implicature is built on what is said, if what is said is closely related to the conventional force of the words used, and if the presence of the implicature depends on the intentions of the speaker, or at least on his assumptions, with regard to the possibility of the nature of the implicature being worked out, then it would appear that the speaker must (in some sense or other of the word know) know what is the conventional force of the words which he is using. (Grice, 1989: 49)

Symmetrically, it is necessary that a hearer be able to understand properly the conventional meaning of a sentence, that is, he must be able to comprehend what the speaker is saying. 
Indeed, Grice emphasizes that the presence of a conversational implicature must be capable of being worked out and that, to work out that a particular conversational implicature is present, the hearer will rely, among other things, on the conventional meaning of the words used (Grice, 1989: 31). ${ }^{2}$

\section{Violative implicature contexts}

As Grice (1989: 30 ff.) illustrates, conversational implicatures arise from either strictly observing or from failing to fulfill, ostentatiously flouting, a maxim or several maxims of conversation. ${ }^{3}$ Grice pointed out at least four ways in which a participant in a talk exchange may fail to fulfill a conversational maxim: first, she may quietly and unostentatiously violate a maxim. In this case, as Grice puts it, she may be liable to act in a misleading way. Secondly, the interlocutor may opt out, saying or indicating that she is unwilling to cooperate in the way the maxim requires. Silence is a classic indicator of the interlocutor's unwillingness to abide by the Cooperative Principle: after having a long discussion, one of the interlocutors stops replying, indicating that she does not want to engage with the ongoing conversation any longer. Thirdly, the participant in a talk exchange may be faced by a clash, being unable, for instance, to fulfill the first maxim of Quantity ('Make your contribution as informative as is required') without violating the second maxim of Quality ('Do not say that for which you lack adequate evidence'). Finally, the participant in a talk exchange may flout a maxim, that is, she may blatantly fail to fulfill it. This is the kind of violation that Grice (1989: 30) calls 'maxim exploitation' and is the case that typically gives rise to a conversational implicature. By 'flouting a maxim,' we must mean flouting it on the level of what is said. Since the communication of the intended content goes through, we cannot assume that a maxim violation takes place at the level of what is communicated. What happens is rather that the speaker flouts the way of satisfying the maxim that relates to the conventional meaning of what she says, that is, by using words that violate it. However, since the speaker is able to convey her intended implicature, the way of satisfying the maxim depending on the implicated meaning is still fulfilled. As Grice puts it, "In these examples, though some maxim is violated at the level of what is said, the hearer is entitled to assume that that maxim, or at least the overall Cooperative Principle, is observed at the level of what is implicated" (Grice, 1989: 33).

\footnotetext{
2 Here is Grice's complete list of data the hearer relies on to work out that a particular conversational implicature is present: "(1) the conventional meaning of the words used, together with the identity of any references that may be involved; (2) the Cooperative Principle and its maxims; (3) the context, linguistic or otherwise, of the utterance; (4) other items of background knowledge; and (5) the fact (or supposed fact) that all relevant items falling under the previous headings are available to both participants and both participants know or assume this to be the case" (Grice, 1989: 31).

3 This distinction between conversational implicatures that arise from observing the maxims and implicatures that arise from flouting them has been explicitly called into question by Bach (2010). Bach argues that implicatures arise only if a maxim is flouted, because, unless a maxim is violated, no implicature would be calculable (Bach, 2010: 131). Against this line of reasoning, and in defense of the Gricean distinction, see Dinges, 2015. Most recently, the distinction between "Observance-Induced inferences" and "Violation-Induced inferences" is the basis of the analysis put forward by Tsohatzidis (2020), which discusses the so-called "problem of composite implicatures."
} 
Assuming that the speaker is able to fulfill the maxim she is blatantly violating and to do so without breaking another maxim because of a clash, and that she is neither opting out nor trying to mislead (given the blatancy of her violation), the hearer will reasonably wonder how the speaker's conversational behaviour can be reconciled with the supposition that she is observing the Cooperative Principle. In defining the notion of conversational implicature, Grice writes:

A man who, by (in, when) saying (or making as if to say) that $p$ has implicated that $q$, may be said to have conversationally implicated that $q$, provided that (1) he is to be presumed to be observing the conversational maxims, or at least the Cooperative Principle; (2) the supposition that he is aware that, or thinks that, $q$ is required in order to make his saying or making as if to say $p$ (or doing so in those terms) consistent with this presumption; and (3) the speaker thinks (and would expect the hearer to think that the speaker thinks) that it is within the competence of the hearer to work out, or grasp intuitively, that the supposition mentioned in (2) is required. (Grice, 1989: 30-31)

The distinction between implicatures that arise in violative contexts by flouting some maxim and those that arise without any infraction is worth emphasizing (see also, in this sense, Colonna Dahlman, forthcoming). According to Grice, conversational implicatures are carried by the saying of what is said (Grice, 1989: 39), and the way of saying it. I contend that, whenever a speaker implicates a content by flouting one or several maxims, her implicature is not only carried by the saying of what is said and the way of saying it, but also by the non-saying of what would have been normal (that is, in compliance with a relevant norm) to say in that particular context. ${ }^{4}$ The flouting of a maxim implies that the speaker is consciously using an utterance, that is not the kind of utterance a hearer would expect to hear in the particular context in which the communicative exchange takes place. ${ }^{5}$ Thus, conversational implicatures that arise in violative contexts depend on the saying of what the speaker says in combination with the non-saying of what the speaker should have said (to abide by a relevant norm) but chose not to say. ${ }^{6}$

\footnotetext{
4 My account differs from the theoretical approach known as 'alternative-based semantics' (Fălăuş, 2013). The main assumption of alternative-based semantics is that, in producing and interpreting sentences, speakers constantly process information about alternatives, that is, other things that could have been said, and were not. My proposal, however, is not about alternatives. The relation between two alternative forms - as the relation between the saying of what is said and the non-saying of what could have been said - is a relation of competition between two concurrent forms that are equally appropriate. By contrast, the relation I am presenting here, between the saying of what is said and the non-saying of what should have been said, is a relation of competition between two forms, of which only one is appropriate. I thank Alexander Dinges for bringing alternative-based semantics to my attention.

5 The "non-saying of what should have been said" may refer to specific words that should have been said and were not said, but not necessarily. As we will see, the non-saying of what should have been said shall rather be understood broadly. For instance, in many cases, involving the violation of the maxim of Relation, the non-saying of what should have been said consists in non-addressing what should have been addressed.

6 The "combination" of saying and non-saying amounts to the following: there is an act of saying that activates a norm that prescribes a different act of saying and hence is not satisfied by the current act of saying. I thank Christian Dahlman for a fruitful discussion on this definition.
} 
Let us take Grice's (1989: 32) garage example, a scenario in which the speaker conveys an implicature according to her communicative intention without involving any maxim violation. A is out of petrol and informs B passing by: 'I am out of petrol.' B replies, 'There is a garage round the corner,' implicating, 'I believe that the garage round the corner is open and has petrol to sell.' In this case, the implicature is conveyed without infringing any maxim: $\mathrm{B}$ is indirectly communicating what she believes to be true and her reply is sufficiently informative, relevant and clear. In Grice's words,

B would be infringing the maxim "Be relevant" unless he thinks, or thinks it possible, that the garage is open, and has petrol to sell; so he implicates that the garage is, or at least may be open, etc. (Grice, 1989: 32)

Since B believes that (it is possible that) the garage is open and has petrol to sell, she is presumably not infringing the maxim 'Be relevant' (nor any other maxim).

Another typical non-violative scenario is the one in which the speaker conveys so-called scalar implicatures. A discovers that all the cookies in the cupboard are gone and asks B, 'Who ate the cookies?' B replies, 'John ate some of the cookies,' implicating, 'John ate some but not all the cookies.' The implicature is conveyed without maxim exploitation: B is indirectly communicating what she believes to be true - that John ate some but not all the cookies - and her reply is sufficiently informative, relevant and clear.

Let us now turn to a violative scenario. In Grice's (1989: 33) famous example of the reference letter, the speaker conveys a conversational implicature by patently infringing the maxims of Quantity and Relation. In writing a testimonial about a pupil who is a candidate for a philosophy job, A says, 'Dear Sir/Madame, Mr. X's command of English is excellent, and his attendance at tutorials has been regular. Yours, etc.' By saying this, A intends to communicate, that is, she is implicating, that Mr. X is not good at philosophy. In this case, A's implicature depends on what she says (' $X$ 's command of English is excellent, etc.') in combination with what she should have said following the maxims of Relation and Quantity, but chose not to say ('Mr. X is good at philosophy' or 'Mr. X is not good at philosophy'). In other words, $\mathrm{A}$ is infringing the maxims of Relation and Quantity that apply to the composition of a valid reference letter. In order to follow these maxims, A should have said whether X is good at philosophy or not. Since A chose not to say what was normal to say in a reference letter for a philosophy job, it is plausible to assume that A intends to communicate a negative judgment indirectly.

Another violative context is the one in which someone gives a completely irrelevant reply, implicating that the topic of conversation is inappropriate (Grice, 1989: 35). At an elegant reception, A says, 'Mr. $\mathrm{X}$ is an arrogant liar, don't you think?' B replies, 'The weather has been quite delightful this summer, hasn't it?' By blatantly flouting the maxim of Relation, B is clearly implicating that she finds A's topic of conversation inappropriate - she does not want to discuss whether Mr. X is an arrogant liar or not - and she wishes to change it. B's implicature depends on what she says ('The weather has been quite delightful this summer, hasn't it?') in combination with what she should have replied following the maxim of Relation, but chose not to say ('You are right, Mr. X is an arrogant liar' or 'You are wrong, Mr. X is a good person'). 
Interestingly, implicatures that arise in violative contexts, depending not only on the saying of what is said but also on the non-saying of what should have been said, require a larger portion of knowledge than that necessitated by implicatures that do not involve any violation. Apart from requiring a general knowledge of the conversational context and its background, and a more specific knowledge of the conventional meaning of the words used, implicatures arising in violative contexts require knowledge of the normative system that is relevant in the context at hand and the awareness that the relevant normative system has been flouted. A speaker is successful in conveying the implicature she intends to convey by using an inappropriate utterance because she can rely on two facts. First, she can trust that her hearer knows the rules that are relevant in the conversational context at hand, that is, her hearer knows how an appropriate utterance would sound; secondly, she relies on the fact that her hearer assumes she is being cooperative, even though she is using an inappropriate utterance. When communication occurs between actors belonging to different cultures, it is thus plausible to expect that some implicatures conveyed in violative contexts be doomed to fail, because actors belonging to different cultures may refer to different normative systems. For instance, in the reference letter scenario, Grice probably imagined that the communicative exchange occurred between two academics of an English-speaking country. Let us imagine, however, a situation in which A sent her testimonial to a colleague in a non-English-speaking country, unaware that in that country an "excellent command of English" is highly valued — in fact, it is a requirement for any philosophy job (for instance, because philosophy employees are expected to hold lectures in English and lecturers who are able to teach in English are quite rare) - and thus a statement guaranteeing a candidate's remarkable proficiency in English happens to be valuable information in a recommendation letter. In this case, the implicature that A intends to convey ('Mr. X is not good at philosophy') might not be grasped by her addressee.

The Gricean distinction between conversational implicatures that arise without infringing the conversational maxims and those that arise by exploiting them results thus in a distinction between pragmatic implications having different epistemic requirements - it might be argued that the latter are epistemically heavier than the former. This argument calls for empirical testing, and I leave this task to further studies. ${ }^{7}$ In the following, I intend to discuss another hypothesis: that implicatures arising without violation, being built only on the saying of what is said, are more strongly tied to the assertion expressed by the utterance used than those arising through maxim exploitation.

\section{False assertion test}

I have argued that the distinction between conversational implicatures that are only carried by the saying of what is said and those that are built on the saying of what is said in combination with the non-saying of what should have been said corresponds to the Gricean distinction between implicatures that arise without exploiting any maxim, and those that, by contrast, arise by means of an exploitation (Grice, 1989:

\footnotetext{
7 For instance, it would be interesting to test the validity of this hypothesis experimentally, with participants belonging to different cultures.
} 
30). Conversational implicatures that arise without maxim exploitation are only built on the saying of what is said, while those that arise by maxim exploitation are carried by the saying of what is said in combination with the non-saying of what should have been said. Now, it might be argued that the former, being built only on the saying of what is said, are more strongly tied to the assertion expressed by the utterance used than the latter. This hypothesis seems confirmed when we look at situations where the assertion generating the implicature is believed to be false by the hearer or where the hearer believes that the generating assertion is believed to be false by the speaker (that is, the hearer believes that the speaker is lying). ${ }^{8}$ Let us first assume the following state of affairs. The speaker intends to convey an implicature $q$ and she knows that by saying $p$, she may succeed in conveying $q$, counting on the fact that her hearer believes that she is conforming to the Cooperative Principle, so she utters $p$. The hearer is able to recognize the speaker's communicative intention and her will to convey $q$; however, he has reasons to believe that $p$ is false. Crucially, in this case, we find that the alleged falsity of the generating assertion $(p)$, that is, its falsity according to the hearer, affects the implicature $(q)$ differently depending on whether the implicature belongs to a violative or a non-violative context. In particular, an allegedly false assertion leads to the rejection by the hearer of the speaker's communicated implicature when the implicature does not involve exploitation and only relates to the saying of what is said ${ }^{9}$ : the implicature is successfully conveyed by the speaker and grasped by the hearer; however, the hearer, believing that the generating assertion is false, assumes that the implicature expresses useless information and he refrains from accepting it in the common ground of information shared with his interlocutor. ${ }^{10}$ By contrast, the alleged falsity of the generating assertion does not

\footnotetext{
${ }^{8}$ Note that here it does not matter whether the assertion is actually false; it is the hearer's believing that the assertion is false or his believing that the speaker believes it to be false that affects the implicature. I am grateful to an anonymous reviewer for urging me to spell out this crucial distinction.

9 Note that implicature rejection presupposes the arising of the implicature. The speaker successfully conveys the implicature she intends to communicate, but the hearer does not accept it. Personally, I would like to argue that implicature rejection leads to the cancellation of the existing implicature, however, I am aware that I would be using the term "cancellation" to refer to cases that were not included in Grice's original definition. Grice discussed two cases of implicature cancellation: a conversational implicature may be explicitly cancelled, "by the addition of a clause that states or implies that the speaker has opted out," or it may be contextually cancelled, "if the form of utterance that usually carries it is used in a context that makes it clear that the speaker is opting out." (Grice, 1989: 39). In both cases, Grice assumed cancellation to be an act of the speaker - it is the speaker who explicitly or implicitly opts out and cancels the implicature. Some scholars find the term "cancellation" inappropriate: since the term "cancellation" presupposes the existence of an implicature, it seems inappropriate to use this term to refer to cases where the speaker does not intend to convey any implicature (see, for instance, Capone, 2009: 59, and Colonna Dahlman, forthcoming, who argues that it would be more appropriate to talk about "suspension"). My proposal is that conversational implicatures may be cancelled following from an act of the speaker (suspension) or following from an act of the hearer (rejection).

10 "Common ground" is here defined in Robert Stalnaker's terms as "presumed background information shared by participants in a conversation" (Stalnaker, 2002: 701), the "background of common knowledge" against which statements and requests are made, questions are asked, and proclamations and commands are issued (Stalnaker, 1973: 448). As highlighted by Stalnaker (2002: 701), the expression "common ground" has its origin in Paul Grice's William James lectures. Here, the term was not defined, however, the British philosopher described certain propositions as having "common ground status" (Grice, 1989: 65, 274).
} 
lead to the rejection of the speaker's communicated implicature when the implicature involves exploitation and relates to the saying of what is said in combination with the non-saying of what should have been said. ${ }^{11}$

Let us take our scenarios, the non-violative (garage scenario and cookies scenario) and the violative ones (reference letter scenario and reception scenario). Crucially, we can see that the alleged falsity of the assertion by which the speaker intends to convey her implicature affects the implicature differently depending on whether the scenario is violative or not. In the garage scenario, if A believes that B's assertion is false - A has reasons to believe that there is no garage round the corner - B's intended implicature (i.e., the assertion that she believes that the garage round the corner is open and has petrol to sell) is rejected. Likewise, in the cookies scenario, if A believes that B's assertion is false - A has reasons to believe that John did not eat any cookies - the implicature (i.e., the assertion that John ate some but not all the cookies) is rejected.

Contrastingly, in the reference letter scenario, even if the addressee of the letter believes that A's assertion is false — he has reasons to believe that Mr. X' command of English is poor - the implicature (i.e., the assertion that Mr. X is not good for a philosophy job) is not rejected. Similarly, in the reception scenario, even if A thinks that $\mathrm{B}$ is expressing a false assertion - according to A, the summer weather was not delightful at all — the intended implicature (i.e., B's invitation to drop the inappropriate topic of conversation) is not rejected.

A similar result holds in situations where the hearer believes that the speaker is lying, saying what she believes to be false - regardless of whether the hearer himself believes $p$ to be false or not. ${ }^{12}$ Again, in this case, the implicature is affected differently depending on whether it arises in violative or in non-violative contexts: in both cases, the implicature is successfully conveyed by the speaker and grasped by the hearer; however, only in the former case (violative contexts), the hearer will consider the implicature as conveying useful information and he will be willing to accept it in the common ground. Interestingly, in non-violative contexts, the hearer, believing that the speaker is lying, asserting what she believes to be false, will assume that the implicature also expresses information that the speaker takes to be false and, obviously, he will refrain from accepting it in the common ground. In other words, in non-violative contexts, the speaker's believing that $p$ is false entails her believing that $q$ is false; while in violative contexts, the speaker's believing that $p$ is false does not entail her believing that $q$ is false. Therefore, in the garage scenario, if A believes that B is lying - according

\footnotetext{
11 Typically, an evident falsity of the assertion uttered by the speaker to convey the implicature is the situation that occurs when the speaker blatantly violates the maxim of Quality, for instance by using metaphorical expressions or ironical utterances. In this case, the evident falsity of the speaker's assertion not only does not lead to rejection but is actually what the arising of the implicature is founded on. The suggestion put forward here is that it is the uttered assertion's relation to the non-saying of what was normal to say (that is, in the case of the assertion's evident falsity, a corresponding true assertion) that leads to successful communication, and that a similar pattern can be observed in other violative implicature contexts.

12 I follow Stokke's (2013) definition of lying: a lie consists of uttering a sentence expressing an assertion the speaker believes to be false, regardless of whether the assertion actually is true or false (I thank an anonymous reviewer for inviting me to consider this distinction).
} 
to A, B does not believe that there is a garage round the corner, B's intended implicature (i.e., the assertion that she believes that the garage round the corner is open and has petrol to sell) is rejected. Likewise, in the cookies scenario, if A believes that B is lying - according to A, B does not believe that John ate any cookies, the implicature (i.e., the assertion that John ate some but not all the cookies) is rejected.

Contrastingly, in the reference letter scenario, if the addressee believes that $\mathrm{A}$ is lying - he has reasons to believe that A thinks that Mr. X' command of English is poor, the implicature (i.e., the assertion that Mr. $\mathrm{X}$ is not good for a philosophy job) is not rejected. Similarly, in the reception scenario, even if A believes that $\mathrm{B}$ is lying - according to him, B does not think that the summer weather was delightful, the intended implicature (i.e., B's invitation to drop the inappropriate topic of conversation) is not rejected.

The following table summarizes my argument.

Table: False assertion test

\begin{tabular}{|c|c|c|}
\hline \multicolumn{3}{|c|}{$\begin{array}{l}\text { Premises: (i) } \mathrm{S} \text { (speaker) intends to convey } q \text { (implicature) by uttering } p \text { (generating assertion); } \\
\text { (ii) } \mathrm{H} \text { (hearer) is able to grasp } q \text {; } \\
\text { (iii) } q \text { is successfully communicated. }\end{array}$} \\
\hline & NON-VIOLATIVE CONTEXTS & VIOLATIVE CONTEXTS \\
\hline $\mathrm{H}$ believes that $p$ is false & $\begin{array}{l}q \text { is rejected, } \\
\text { as } \mathrm{H} \text { assumes that } q \text { expresses } \\
\text { useless information }\end{array}$ & $\begin{array}{l}q \text { is not rejected, } \\
\text { as } \mathrm{H} \text { assumes that } q \text { may express } \\
\text { useful information even though } \\
\text { he believes that } p \text { is false }\end{array}$ \\
\hline $\begin{array}{l}\mathrm{H} \text { believes that } \mathrm{S} \text { believes that } p \\
\text { is false }\end{array}$ & $\begin{array}{l}q \text { is rejected, } \\
\text { as } \mathrm{H} \text { assumes that } q \text { expresses } \\
\text { information that is false } \\
\text { according to } \mathrm{S}\end{array}$ & $\begin{array}{l}q \text { is not rejected, } \\
\text { as } \mathrm{H} \text { assumes that } q \text { may express } \\
\text { information that is true accord- } \\
\text { ing to } \mathrm{S} \text { (even though } \mathrm{S} \text { believes } \\
\text { that } p \text { is false) }\end{array}$ \\
\hline
\end{tabular}

The presumed falsity of the generating assertion or the presumption that the speaker is lying leads thus to the rejection by the hearer of the speaker's communicated implicature only if the implicature does not involve maxim violation, while an implicature that involves violation is not rejected even though the hearer believes that the generating assertion is false or even though the hearer believes that the speaker is lying. I argue that this is because the latter kind, differently from the former, does not only relate to the saying of what is said, but relates to the saying of what is said in combination with the non-saying of what should have been said.

\section{Conclusion}

The aim of this paper was to point out a new distinction in Grice's analysis of conversational implicatures. The claim is that some conversational implicatures are not only built on the saying of what is said, but rather on the saying of what is said in combination with the non-saying of what should have been said. The distinction between implicatures that only relate to the saying of what is said 
and those that are built on the saying of what is said in combination with the non-saying of what should have been said corresponds to the Gricean distinction between conversational implicatures that arise without exploiting any maxim, and those that, by contrast, arise by means of an exploitation (Grice, 1989: 30). Conversational implicatures that arise without maxim exploitation are only carried by the saying of what is said, while implicatures that arise in violative contexts are carried by the saying of what is said in combination with the non-saying of what should have been said. This distinction seems to justify two claims. First, it has been argued that conversational implicatures have different epistemic requirements depending on whether they arise in violative or non-violative contexts. Implicatures that arise in violative contexts require a larger portion of knowledge than that necessitated by implicatures that do not involve any violation - apart from requiring a general knowledge of the conversational context and its background, and a more specific knowledge of the conventional meaning of the words used, implicatures arising in violative contexts require knowledge of the normative system that is relevant in the conversational context at hand and the awareness that the relevant normative system has been flouted.

Secondly, it has been argued that implicatures arising in non-violative contexts, being built only on the saying of what is said, are more strongly tied to the assertion expressed by the utterance used than implicatures arising in violative contexts. In fact, assuming that the hearer believes the assertion generating the implicature to be false or assuming that the hearer believes that the speaker is lying (saying what she believes to be false), it has been shown that only implicatures arising in violative contexts have the potential to survive. This result has an interesting implication in situations where the speaker actually lies in uttering $p$. Let us assume the following situation. The speaker intends to convey $q$ in order to achieve some goal and she knows that by saying $p$, she may succeed in conveying $q$, counting on the fact that her hearer believes that she is conforming to the Cooperative Principle; the speaker believes that $p$ is false, however, she believes that uttering $p$ is the most effective way to communicate $q$, so she utters $p$. In this situation, the speaker's conversational behaviour leads to different outputs depending on whether the speaker's implicature involves maxim exploitation or not. In both cases the speaker successfully conveys the implicature she intends to communicate. However, assuming that the hearer realizes that the speaker is lying, the false assertion test has shown that the speaker can still make use of her intended implicature in the former case, but not in the latter. In both cases, the speaker is lying — she is uttering what she believes to be false. However, in the violative context, she will succeed in adding her intended implicature in the common ground, even though the hearer knows that she is lying. Hence, her insincere behaviour does not lead to communicative failure and it is plausible to expect that she will not be held liable to act in a misleading way.

Acknowledgements I would like to express my deep gratitude to Christian Dahlman, Alexander Dinges, and Julia Zakkou, for very useful feedback and discussions. Moreover, I am very grateful to an anonimous reviewer of Acta Analytica for her/his very valuable comments.

Funding Open access funding provided by Lund University. 


\section{Declarations}

Conflict of interest The author declares no competing interests.

Open Access This article is licensed under a Creative Commons Attribution 4.0 International License, which permits use, sharing, adaptation, distribution and reproduction in any medium or format, as long as you give appropriate credit to the original author(s) and the source, provide a link to the Creative Commons licence, and indicate if changes were made. The images or other third party material in this article are included in the article's Creative Commons licence, unless indicated otherwise in a credit line to the material. If material is not included in the article's Creative Commons licence and your intended use is not permitted by statutory regulation or exceeds the permitted use, you will need to obtain permission directly from the copyright holder. To view a copy of this licence, visit http://creativecommons.org/licen ses/by/4.0/.

\section{References}

Bach, K. (2010). Impliciture vs explicature: What's the difference? In B. Soria, \& E. Romero (Eds.), Explicit communication. Robyn Carston's pragmatics (pp. 126-137). London-New York: Palgrave Macmillan.

Borg, E., \& Fisher S. (forthcoming). Semantic content and utterance context: A spectrum of approaches. In P. Stalmaszczyk (Ed.), The Cambridge handbook of the philosophy of language. Cambridge: Cambridge University Press.

Capone, A. (2009). Are explicatures cancellable? Toward a theory of the speaker's intentionality. Intercultural Pragmatics, 6(1), 55-83.

Colonna Dahlman, R. (forthcoming). Entailment, presupposition, implicature. In P. Stalmaszczyk (Ed.), The Cambridge handbook of the philosophy of language. Cambridge: Cambridge University Press.

Dinges, A. (2015). Innocent implicatures. Journal of Pragmatics, 87, 54-63.

Fălăuş, A. (2013). Introduction: Alternatives in semantics and pragmatics. In A. Fălăuş (Ed.), Alternatives in Semantics (pp. 1-35). London-New York: Palgrave Macmillan.

Grice, P. (1989). Studies in the Way of Words. Harvard University Press.

Stalnaker, R. (1973). Presuppositions. Journal of Philosophical Logic, 2, 447-457.

Stalnaker, R. (2002). Common ground. Linguistics and Philosophy, 25, 701-721.

Stokke, A. (2013). Lying and asserting. The Journal of Philosophy, 110(1), 33-60. https://doi.org/10. 5840/jphil2013110144

Tsohatzidis, S. L. (2020). An inferential impasse in the theory of implicatures. In S. L. Tsohatzidis (Ed.), Truth, force, and knowledge in language. Essays on semantic and pragmatic topics (pp. 285-296). Berlin-Boston: De Gruyter Mouton.

Publisher's Note Springer Nature remains neutral with regard to jurisdictional claims in published maps and institutional affiliations. 